
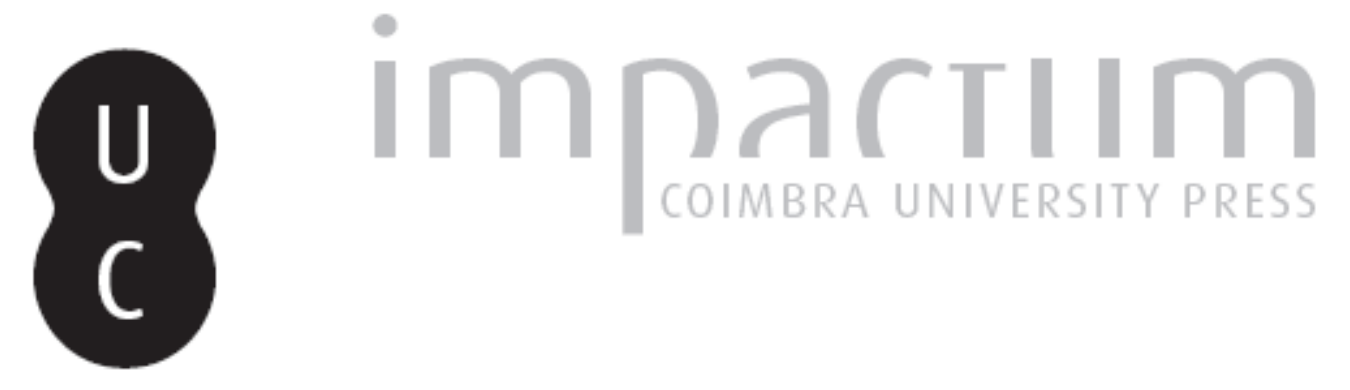

\title{
O que nos dizem os escândalos políticos sobre os media?
}

\author{
Autor(es): Paixão, Bruno
}

Publicado por: Imprensa da Universidade de Coimbra

URL persistente:

URl:http://hdl.handle.net/10316.2/39194

DOI:

DOI:http//dx.doi.org/10.14195/2183-6019_2_12

Accessed : $\quad$ 26-Apr-2023 15:03:54

A navegação consulta e descarregamento dos títulos inseridos nas Bibliotecas Digitais UC Digitalis, UC Pombalina e UC Impactum, pressupõem a aceitação plena e sem reservas dos Termos e Condições de Uso destas Bibliotecas Digitais, disponíveis em https://digitalis.uc.pt/pt-pt/termos.

Conforme exposto nos referidos Termos e Condições de Uso, o descarregamento de títulos de acesso restrito requer uma licença válida de autorização devendo o utilizador aceder ao(s) documento(s) a partir de um endereço de IP da instituição detentora da supramencionada licença.

Ao utilizador é apenas permitido o descarregamento para uso pessoal, pelo que o emprego do(s) título(s) descarregado(s) para outro fim, designadamente comercial, carece de autorização do respetivo autor ou editor da obra.

Na medida em que todas as obras da UC Digitalis se encontram protegidas pelo Código do Direito de Autor e Direitos Conexos e demais legislação aplicável, toda a cópia, parcial ou total, deste documento, nos casos em que é legalmente admitida, deverá conter ou fazer-se acompanhar por este aviso.

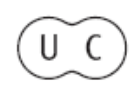


revista de comunicação,

jornalismo e espaço público

2

Periodicidade

Semestral

Imprensa da Universidade de Coimbra Coimbra University Press

\section{mediapolis}

tema

os desafios dos media

de serviço público

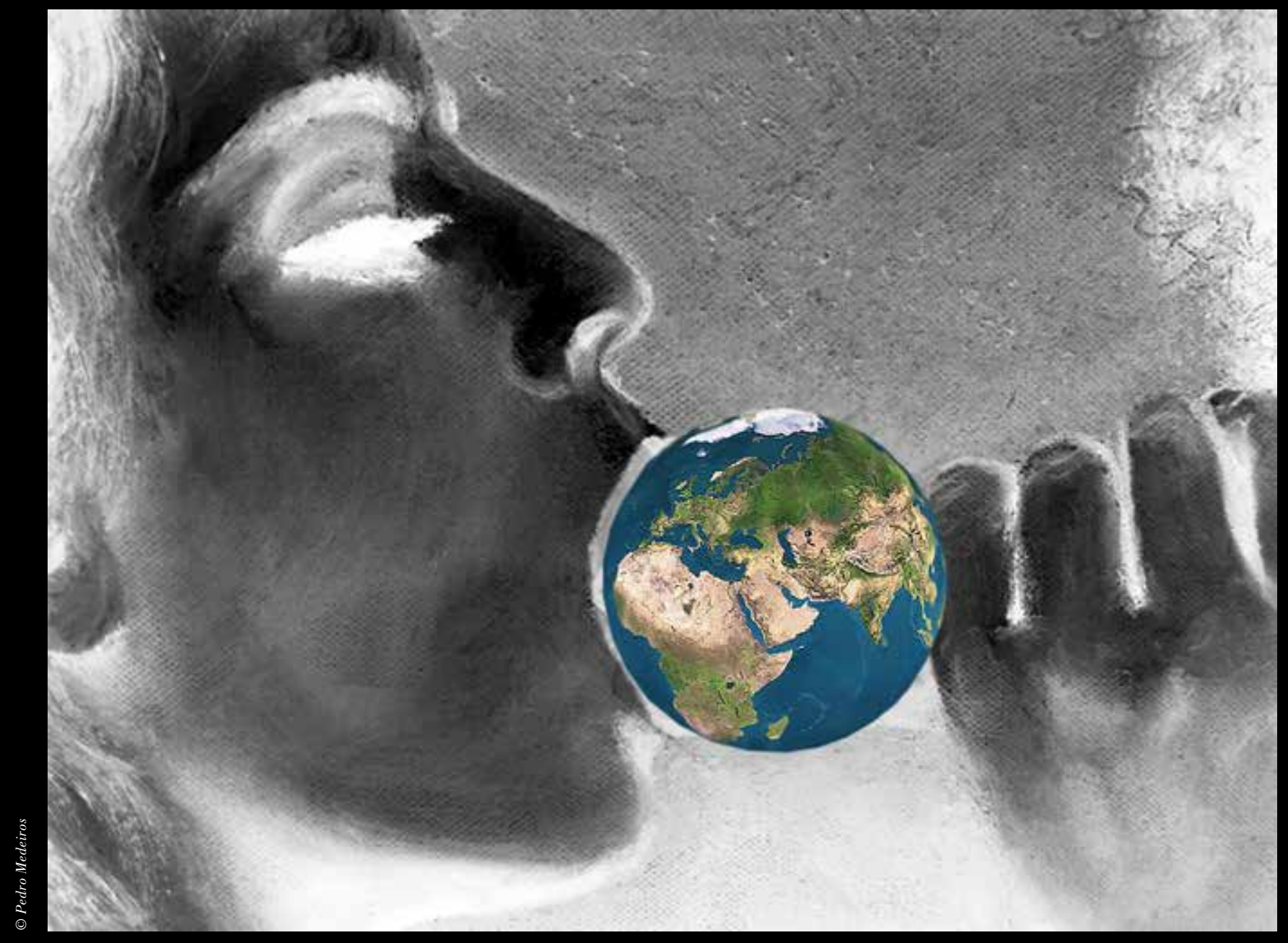




\section{Bruno Paixão}

\section{O que nos dizem os escândalos políticos sobre os media?}

What do the political scandals say about the media?

\section{Resumo:}

O escândalo político é um fenómeno social que tem alcançado preponderância nas sociedades democráticas contemporâneas. Isso deve-se sobretudo a uma maior atenção jornalística que é concedida aos casos. Os media concedem à sociedade perceções sobre temas e acontecimentos, influindo sobre a inteleção dos cidadãos.

Neste trabalho analisamos alguns traços da cobertura jornalística do escândalo político em Portugal ao longo do período democrático, entre 25 de abril de 1974 e 25 de abril de 2014, pretendendo cotejar padrões de cobertura jornalística a partir das peças extraídas de quatro jornais semanários generalistas de expansão nacional - Expresso, O Jornal, O Independente e Sol. Como revela o nórdico Mats Ekstrom (2000), numa frase lapidar que se poderia aditar a este trabalho sem causar surpresa, os escândalos encaixam-se numa cultura de notícias e de media «em que a oferta do que é chocante, espetacular, sensacional e anormal é a estratégia fundamental para supostamente atrair audiências».

Palavras-chave: Escândalo político, corrupção política, comunicação política, jornalismo político.

\section{Abstract:}

Political scandals are a social phenomenon of ascending relevance in modern democratic societies. This is mostly the result of the profuse media coverage granted to such cases. Consequently, the media offer society perceptions on topics and events that impact the intellection of citizens. The present paper focuses on some aspects of the press coverage of political scandals in Portugal over the democratic period from 25 April 1974 to 25 April 2014. It seeks to collate press coverage patterns, based on the clippings of four weekly newspapers of general circulation in the country - Expresso, O Jornal, O Independente and Sol.

As the Nordic sociologist Mats Ekstrom (2000) highlights in a bold statement which could, unsurprisingly, be quoted herein, scandals fit perfectly into a news and media culture "in which the offering of what is shocking, spectacular, sensational and abnormal is the most fundamental strategy for attracting and fascinating presumptive audiences".

Keywords: Political scandal, political corruption, political communication, political journalism. 


\section{Introdução}

É sabido que um dos esforços mais significativos dos políticos consiste em influenciar o conteúdo das notícias. O que converge para enfatizar a proeminência que os media têm nas sociedades modernas. Como sintetiza Manuel Castells (2013: 267), “a política mediática é a forma de fazer política nos e através dos meios de comunicação". Nesse sentido, reforça-se a convicção de que hoje a política está diligentemente centrada nas suas capacidades de mediatização. Mas, para tal acontecer, é necessário que políticos e jornalistas cultivem uma relação que pode ser caracterizada como de interdependência, em que ambos colham daí vantagens: os jornalistas porque angariam informação privilegiada; e os políticos porque veem os media seguir o enfoque pretendido.

Antes de mais, é necessário, como acautela Ana Cabrera, "partir do princípio de que os jornais não são entidades neutras, pelo contrário. Eles encerram, em qualquer época, lutas pelo poder, interesses económicos, sociais e políticos" (Cabrera,
2011: 7). Nesse âmbito, o escândalo político - enquanto fenómeno mediático que incide sobre alegadas transgressões de normas ou valores morais, cometidas por sujeitos políticos, podendo estas causar danos à sua reputação e inviabilizar as suas pretensões de poder -, concede-nos uma tónica útil e relevante para o estudo e o aprofundamento do papel dos media na sociedade.

Cremos em que a exposição de circunstâncias geradoras de escândalos políticos desempenha uma importante parte na ideologia profissional do jornalismo. A investigação de instituições poderosas e de figuras públicas é essencial para o cumprimento das metas profissionais dos jornalistas, trazendo alguma verdade ao mito dos media que os reputa de "quarto poder". Contudo, seria desproporcionado dizer que na caça aos escândalos os jornalistas são meros assistentes, sem qualquer papel ativo, pois são eles que optam por dar um determinado enfoque a uns casos, em vez de outros, e sabem copiosamente como fazer para que o vulcão se mantenha em permanente erupção.

\section{A anatomia do escândalo}

Ao designarem um caso como escandaloso, os media estão a ameaçar a reputação e a posição de poder do político envolvido (Thompson, 2002; Lull e Hinerman, 1997; Markovits e Silverstein, 1988). Qualquer coisa que possa ser criticada ou vista como uma transgressão de normas pode hoje receber este rótulo nos noticiários, mesmo quando os próprios media tratam o assunto como uma história menor.

Considerando que a alteração das sociedades trouxe inevitavelmente uma nova visibilidade que supera a pequena escala localizada, o escândalo passou a acontecer nas sociedades modernas, necessariamente, por via da ação dos media. Isto não significa que os escândalos, a um nível mais localizado, como numa associação local, por exemplo, não tenham ocorrido ou não continuem a ocorrer sem a intervenção da comunicação social. Nesta ótica, como Thompson vem a reconhecer, realçamos que numa esfera global não há outra forma de tornar um caso público e com ampla visibilidade sem a necessária intervenção de meios 
abertos e massivos como a comunicação social (Thompson, 2002: 46-47). A nova visibilidade proporcionada pelos media, incluindo o on-line, veio possibilitar que muitos eventos que não estavam ao alcance das massas passassem a estar agora visíveis, ao mesmo tempo que deixou mais incontroláveis os fluxos de informação que se movimentam na cena pública. $O$ escândalo, de forma geral, apresenta seis características frequentes, embora não cumulativas.

i. Presume-se a infração de valores, normas ou códigos morais por parte de um sujeito ligado ao campo político;

ii. Existe a possibilidade de a transgressão poder desencadear a desaprovação pública pela afronta aos valores e normas estabelecidos, mesmo dizendo respeito apenas a formalidades rotineiras da vida social;

iii. Deve surgir a manifestação da desaprovação por parte de sujeitos não participantes, pois é necessário que alguns indivíduos se sintam incomodados e escandalizados com a transgressão; iv. A revelação de uma transgressão é suscetível de provocar prejuízo à reputação de um indivíduo;

v. Na maior parte dos casos há uma tentativa de segredo ou ocultação dos factos por parte dos sujeitos implicados;

vi. Para o escândalo ocorrer é indispensável que o assunto transite para o conhecimento público, o que acontece nas sociedades modernas através dos media.

Embora haja divergências naquilo que é o conceito de escândalo político, sobretudo quando se trata de o confinar ao plano do estrito exercício político (Markovits e Silverstein, 1988; Midtbo apud Allern e Pollack, 2012: 14) ou de o estender também a ações da vida privada dos seus protagonistas - corrente que encontra em Thompson (2002: 124-127) a principal referência - a literatura apresenta-nos as tipologias dos escândalos mais frequentes: os de poder, os financeiros e os sexuais. A disparidade cultural, funcionando como uma ecosfera política, tem ela própria intervenção na ocorrência dos tipos de escândalos políticos que vão germinando em cada sociedade. Veja-se, a título de exemplo, a aplicabilidade da tipificação do escândalo político fornecido por Thompson (2002), sustentando este que as três tipologias mais frequentes cingem-se aos escândalos de poder, financeiro e sexual. Parece claro que o professor de Cambridge elaborou esta segmentação centrado no seu contexto anglo-americano, ou não encontrássemos em Portugal a existência de um número considerável de casos sem amparo nesse enquadramento, tendo-nos levado a propor, em consequência, uma nova estirpe.

A nova tipologia que observamos, denominada "escândalo político de conduta", que vem trazer pertinência a várias ocorrências que não se ajustam às três tipologias principais estabelecidas por Thompson, reporta-se a contravenções de comportamentos que são moral e culturalmente reprováveis. Visando um protagonista político, tanto pode englobar furtos, homicídios, agressões e violência (na forma tentada ou consumada), comportamento indecoroso em público, consumo de substâncias proibidas ou fraude académica (incluindo plágio e obtenção irregular de graus académicos), entre 


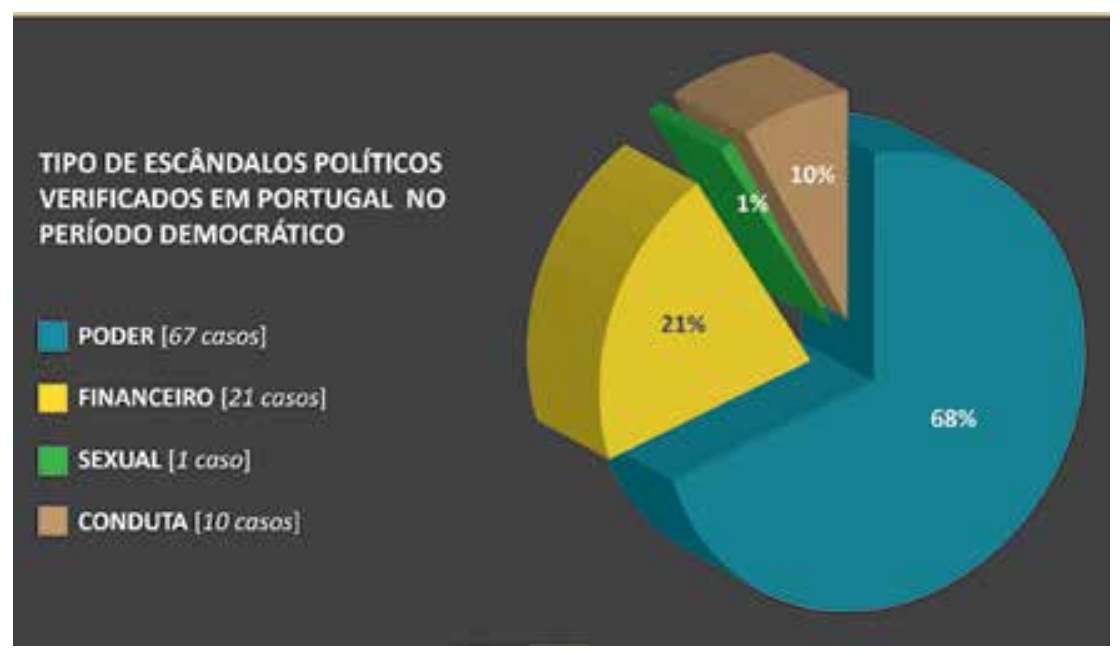

muitas outras prevaricações que podem derrubar os capitais de reputação dos políticos e enfraquecer a sua legitimidade perante os cidadãos. Inserem-se nesta catalogação casos como o gesto de "cornichos" dirigido pelo ministro Manuel Pinho a um deputado da oposição (que conduziu à sua demissão), o furto dos gravadores de jornalistas da Sábado pelo deputado Ricardo Rodrigues no decurso de uma entrevista, o alegado envolvimento de Duarte Lima no homicídio da sua cliente Rosalina Ribeiro ou as dúbias licenciaturas de José Sócrates e Miguel Relvas. Em suma, tal como propomos, a segmentação dos casos deve, pois, passar a desdobrar-se em quatro tipologias: escândalo político de poder, financeiro, de conduta e sexual (ou da vida íntima) ${ }^{1}$.

Embora os escândalos políticos financeiro e de poder sejam os mais frequentes, como podemos observar no primeiro gráfico, e de o escândalo de

1 Entendemos que a terminologia "escândalo sexual" deve ser substituída por "escândalo da vida íntima", por aludir a casos não apenas sexuais mas também conjugais e cuja frequência em Portugal é praticamente nula, ao contrário do que acontece nos países anglo-americanos. conduta se revelar expressivo, como sustentámos, é o sexual que motiva alguma reflexão mais escavada, no que concerne ao campo dos media. De acordo com o gráfico 1, os jornalistas portugueses, em matéria de cobertura da vida sexual dos políticos, estão distantes do que é típico na imprensa dos países anglo-saxónicos, onde as transgressões de ordem sexual protagonizadas por políticos colhem tradição de exaustiva exposição e mesmo de quase humilhação pública pelos media, facto notado por Thompson (2002: 164). Em Portugal, pelo contrário, raros foram os casos que se tornaram conhecidos ${ }^{2}$. Nesta tipologia encontram-se incluídas as revelações sobre a vida privada de um político, digam elas respeito a infrações punidas por lei (como a pedofilia ou a prostituição, por exemplo) ou simplesmente a "formas de conduta impróprias ou inconvenientes", como classifica

2 Podemos aqui referir o mais emblemático e quase solitário caso "Ballet Rose", que marcou a ditadura de Salazar na década de 1960, envolvendo prostituição e pedofilia. E, mais tarde, já quase 30 anos volvidos sobre a implantação da democracia, só o caso de pedofilia Casa Pia voltou a suscitar ampla cobertura mediática.
Figura 1

A representação das tipologias de escândalo político.
Thompson (2002:154). Nesse sentido, apropriada seria a migração do epíteto "escândalo sexual" para "escândalo da vida íntima". Nesta matéria Portugal parece coincidir com a mesma linha liberal que se verifica em países como a França ou o Brasil. Ainda assim, afastando-se de um certo "voyeurismo", os jornalistas não são isentados da perceção de que cometem abusos ao exporem a vida privada dos visados, como revela o gráfico da figura 2, referente ao estudo de opinião que realizámos em dezembro de 2014, feito via online, utilizando a aplicação Google Forms: 78,2\% dos 1419 respondentes, consideram que os media cometem abusos na exposição da vida privada dos seus alvos.

\section{$O$ interesse dos media pelo escândalo}

A voragem de fornecer notícias ao público, de as divulgar antes da concorrência e de publicar a "cacha" tem contribuído para precipitar casos escandalosos, ainda que por vezes estes se afigurem insustentados. Uma característica de alguns escândalos 
Figura 2

Questão colocada sobre se os media

cometem abusos na exposição da privacidade.

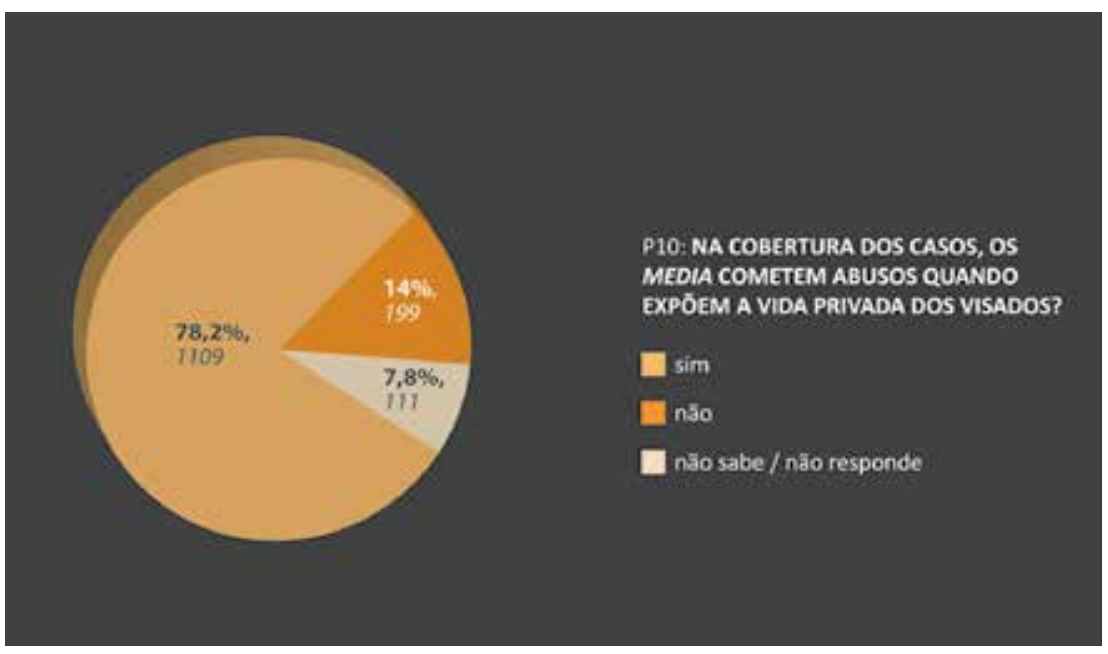

políticos é que eles começam como algo relativamente menor e só depois se convertem num caso mais grave. Por vezes, o caso evolui muito por força de declarações e de um emaranhado de justificações, negações ou atitudes que acabam por configurar novas violações de normas.

Os escândalos encaixam-se numa cultura de notícias e de media "em que a oferta do que é chocante, espetacular, sensacional e anormal é a estratégia fundamental para supostamente atrair audiências" (Ekstrom, 2000). O sensacionalismo tem-se tornado mais notório com o avanço dos meios tecnológicos e a correspondente oferta informativa, onde estão incluídos os canais noticiosos que transmitem 24 horas por dia, "com incessantes informações de última hora para saciar o apetite de sensacionalismo, ávido de novidades" (Castells, 2013: 333-334), mas também pelo facto de a Internet permitir uma imediata difusão viral, com milhões de partilhas instantâneas de factos controversos.

A importância estratégica que o jornalismo avoca na atualidade reside, de acordo com alguns autores, não só no facto de dar visibilidade aos acontecimentos mas também na capacidade de determinar aquilo que se transformará em notícia, construindo e reconstruindo significados que atuam sobre a perceção social (Tuchman, 1978; Cabrera, 2001). Nessa perspetiva, os escândalos políticos são frequentemente contados como uma encenação teatral onde o palco pertence a um vilão, havendo como cenário uma prevaricação reprovável. As ações vão sendo descritas durante o ato, com pormenores aliciantes para o público. Como notam os nórdicos Sigurd Allern e Ester Pollack, “os escândalos captam a atenção dos sites, ajudam a vender jornais e aumentam as audiências dos canais televisivos. Nesse contexto, os jornalistas não exercem apenas o papel de repórteres, eles também interpretam e, em diferentes graus, direcionam o curso do escândalo" (Allern e Pollack, 2012: 9). De acordo com Bell (1998: 64), “os jornalistas não constroem apenas artigos, mas também histórias, com estrutura, ordem, pontos de vista e valores". Os jornalistas têm assim uma ação crucial nos escândalos, por serem eles a definir os ângulos do caso, a escolha das vozes ou as fontes da notícia.
Nesse aspeto, no processo de produção noticiosa, a relação entre o jornalista e as suas fontes é um dos mais complexos temas. Estas fontes garantem aos media um volume de informação que é a sua matéria-prima e que acaba por resultar na peça informativa que chega finalmente ao público.

Os dados coligidos permitem-nos apurar que as peças sem referência a qualquer fonte são as que têm maior representatividade no âmbito do escândalo político, encontrando-se em 40,5\% dos casos, ou seja, em 1917 peças. Destas, 474 não são assinadas, representando o valor numérico mais elevado entre as peças deixadas sem a referência ao seu autor. O número elevado de peças sem referência às fontes, acalenta a ideia de que, no processo de negociação entre jornalistas e fontes, os primeiros acedam em acomodar informação sob o manto do anonimato. Por um lado, isso pode ser compreensível dado que, de outra forma, o jornalista não obteria a informação desejada ou perderia a "vantagem competitiva no acesso a informação qualificada" (Fidalgo, 2009: 128). Mas, por outro, a sua contribuição para o "dever ser" deontológico de 
privilegiar a identificação das fontes acaba por anular-se.

Uma peça que mostra as falhas da investigação, ainda que irrelevantes, irá por certo condicionar a perceção pública face à justiça. Da mesma forma, ao ignorar essas falhas e ao expor as dúvidas que pairam sobre o papel dos atores políticos envolvidos, é promovida uma condenação popular antecipada. Enquanto o enredo se revelar estimulante e promissor, a peça não sai de cena e o cartaz mantém-se nos escaparates mediáticos. Dessa forma, “um escândalo não é apenas algo que é revelado, mas também algo que é mostrado, relatado, encenado e mantido vivo dia após dia" (Ekstrom e Johansson, 2008: 72).

A maioria dos autores vê uma afinidade clara entre o escândalo e os media: "o escândalo vende", sintetiza Thompson (2002: 59). Embora nenhum estudo de análise dos media tenha concretamente demonstrado esta premissa, curiosamente estabeleceu-se uma certa unanimidade em torno dela. Com alguma contundência, Thompson nota que aqueles que mais têm a ganhar em alimentar o espaço público com escândalos "têm poucas razões para se abster de lucrar com isso quando a oportunidade se apresenta" (Thompson, 2002: 21). Como também havia mais cautelosamente concluído Paixão (2010: 181), o escândalo pode manter "estimulante e atrativa uma edição de jornal" e, em tempo de declínio e quebra nas tiragens, pode inclusive ajudar a segurar as audiências. De acordo ainda com Thompson, os órgãos de comunicação têm interesse financeiro na venda de temas como os escândalos, pois estes "fornecem histórias vivas, picantes, que podem ajudar esplendidamente a conduzir esse objetivo" (Thompson, 2002: 59). Tal como refere Mar de Fontcuberta, "os índices de audiência e as tiragens converteram-se nos verdadeiros motores da criação, permanência ou desaparecimento de certos conteúdos" (Fontcuberta, 1999: 35). Esta análise é corroborada por Baum (2002), ao notar que grande parte dos media americanos são empresas comerciais que têm de se preocupar em atrair os tipos de clientelas e anunciantes que lhes permitam obter lucros substanciais. Baum justifica ainda o uso persistente do infotainment com os dados sobre audiência, advogando que estes revelam a propensão do público para o entretenimento, ao mesmo tempo que evitam notícias de certa complexidade, o que legitima a apresentação das notícias com esse enfoque.

Este diagnóstico não isenta a determinação económica que emana do capitalismo globalizado, uma vez que este fez sucumbir princípios de cidadania face à prevalência de princípios de consumo, trazendo como consequência uma subordinação dos media e do jornalismo, nos planos tanto económico como profissional, ao financiamento exterior, aos sponsors e aos anúncios publicitários. O que, como nota Isabel Ferin Cunha, só acontece se houver "boa imprensa", "opinião favorável” ou “omissões convenientes", determinando esse apoio dos grandes grupos económicos e financeiros a "continuidade, o lucro e os postos de trabalho num determinado órgão de comunicação" (Cunha, 2015a e 2015b). A investigadora e professora da Universidade de Coimbra considera que:

"A assunção que a informação $e$ o jornalismo, tanto nos media públicos como privados, constituem áreas que devem ser geridas como 
um qualquer negócio, traz como consequência a fragilização dos profissionais, atormentados por ameaças de redução de custos isto é, ameaçados constantemente de despedimentos e de precarização de funções - tornando-os vulneráveis perante as pressões de governantes e de empresas com interesses nos grupos mediáticos" (Cunha, 2015a)

Não será linear a análise que conjuga a publicação de escândalos com o volume de vendas, sobretudo no presente contexto, em que é patente o declínio generalizado na receita das empresas de media, levando a fortes restrições e mesmo ao encerramento de diversas publicações, verificando-se em paralelo o acesso massivo à informação gratuita, a que não são alheias as modificações introduzidas pela era digital (Fenton, 2010). Essa lógica de mercado, sustenta o sociólogo francês Rémy Rieffel (2003:148), repercute-se no produto jornalístico, ele próprio cada vez mais direcionado para o entretenimento e para a informação-espetáculo. Este processo de "tabloidização", segundo Kees Brants
(2005: 47), caracteriza-se pelo crescimento da importância do sensacionalismo e das notícias que suscitam um certo "voyeurismo", ou seja, "o infotainment situa-se entre dois polos e mistura elementos de informação política em programas de entretenimento, ou características de entretenimento em programas tradicionalmente informativos" (Brants, 2005: 50). Esta posição é também realçada por Figueiras (2012: 7), ao considerar que "a cobertura jornalística se estruturou na política-espetáculo: na personalização, na imagem, na dramaticidade e em pseudocrises".

Noutra perspetiva, atribui-se à ação da comunicação social uma função de vigilância e denúncia relativamente a transgressões cometidas pelos políticos, o que gera como efeito uma conformação dos cidadãos, que ficam assim inativos, dada a sua conciliação tácita com o desempenho dos media. Esta utilidade dos jornalistas é, por Fitoussi e Rosanvallon, apelidada de "utopia positiva dos meios de comunicação", na perspetiva de uma crença pela sociedade de que os media "serão capazes de resolver as questões que a democracia não consegue solucionar no terreno das instituições políticas". Mas, como advertem os autores, esta crença pode conduzir a "uma espécie de utopia perigosa", dado que os meios de comunicação podem pensar ser "os verdadeiros representantes do povo (...). No limite, sonham inclusivamente ser produtores de decisão política ou judicial" (Fitoussi \& Rosanvallon, 1997: 131).

\section{Opções metodológicas e análise de (outros) dados}

No que concerne à observação empírica do presente trabalho, interessa-nos perscrutar qual a cobertura jornalística do fenómeno do escândalo político nos semanários portugueses de referência, ao longo do período democrático, cotejando se é possível identificar padrões de cobertura jornalística, bem como aferir a existência de tendências evolutivas. Para tal, analisámos as peças presentes no caderno principal das edições dos jornais Expresso, O Jornal, O Independente e Sol, no período 1974-2014, resultando isso num apuramento de 2101 edições com escândalos políticos, das quais 
extraímos 4739 peças noticiosas, tendo sido apurados 99 casos. Empregámos, na nossa análise, a mensuração dos dados recorrendo à EIM (Escala de Intensidade Mediática), que consiste num padrão de medição caracterizado por uma sequência de valores e de classes, aferidos através de um algoritmo construído com base num conjunto de operações numéricas, visando mensurar e classificar ocorrências mediáticas ${ }^{3}$. Com a aplicação desta escala torna-se exequível o estabelecimento de um ranking, tendo em vista graduar a intensidade que um tema tem nos media, permitindo não só atribuir-lhe um valor numérico concreto na escala, como também enquadrá-lo quantitativamente numa classificação segmentada em dez níveis. Em síntese, a Escala de Intensidade Mediática consiste num método matemático baseado em variáveis integradas presentes nas peças jornalísticas, como o tipo de página, a presença do objeto no título, a

3 Cfr. Tese de doutoramento de Bruno Paixão, intitulada "A mediatização do Escândalo Político em Portugal no período democrático", defendida em 17 de dezembro de 2015, na Universidade de Coimbra. localização da peça, o espaço ocupado ou a valorização gráfica, com o objetivo de aferir o relevo que um caso propaga num determinado número de órgãos de informação, num dado período. Os 99 casos em análise são os seguintes:

\begin{tabular}{|c|c|c|c|}
\hline \multicolumn{4}{|c|}{$\begin{array}{l}\text { Casos iniciados no período de Revolução } \\
\text { Democrática (1974-1976) }\end{array}$} \\
\hline 1 & EIM 0,84 & Spínola / Wallraff & poder \\
\hline \multicolumn{4}{|c|}{ Casos iniciados no período de } \\
\hline \multicolumn{4}{|c|}{ Consolidação Democrática (1976-1986) } \\
\hline 2 & EIM 0,30 & Processo das Armas & financeiro \\
\hline 3 & EIM 0,43 & Soares Carneiro e os & poder \\
\hline & & internamentos em Angola & \\
\hline 4 & EIM 0,62 & A dívida de Sá Carneiro & financeiro \\
\hline 5 & EIM 0,41 & Cafés Delta & financeiro \\
\hline 6 & EIM 0,16 & $\begin{array}{l}\text { Adelaide Paiva e os rumores } \\
\text { de tráfico de droga }\end{array}$ & financeiro \\
\hline 7 & EIM 0,23 & Dossiê Mesquita Machado & poder \\
\hline 8 & EIM 0,21 & $\begin{array}{l}\text { Custódio Simões acusado de } \\
\text { fraude }\end{array}$ & poder \\
\hline 9 & EIM 1,49 & $\begin{array}{l}\text { Subsídios de Rui Amaral sob } \\
\text { suspeita }\end{array}$ & poder \\
\hline 10 & EIM 0,44 & DOPA e o tráfico de divisas & financeiro \\
\hline \multicolumn{4}{|c|}{ Casos iniciados no período de Transformação } \\
\hline \multicolumn{4}{|c|}{ Estrutural (1986-2008) } \\
\hline 11 & EIM 1,80 & Viagens-Fantasma & poder \\
\hline 12 & EIM 0,18 & CEEETA & poder \\
\hline 13 & EIM 0,21 & $\begin{array}{l}\text { Irregularidades de Monterroso } \\
\text { na Câmara da Nazaré }\end{array}$ & poder \\
\hline 14 & EIM 7,85 & Processo da Saúde & poder \\
\hline 15 & EIM 1,41 & TDM/Emaudio & poder \\
\hline 16 & EIM 1,31 & A Sisa de Cadilhe & poder \\
\hline 17 & EIM 6,32 & Fax de Macau & poder \\
\hline 18 & EIM 0,51 & $\begin{array}{l}\text { Oliveira e Costa perdoa } \\
\text { dívidas a empresas }\end{array}$ & poder \\
\hline 19 & EIM 0,09 & $\begin{array}{l}\text { Irregularidades de Mário } \\
\text { Pedra em Valença }\end{array}$ & poder \\
\hline 20 & EIM 0,36 & Partex & financeiro \\
\hline 21 & EIM 0,05 & A manta da TAP & conduta \\
\hline 22 & EIM 1,02 & Fraude na UGT & poder \\
\hline 23 & EIM 1,00 & Monte dos Frades & financeiro \\
\hline 24 & EIM 0,29 & A casa de Couto dos Santos & poder \\
\hline 25 & EIM 0,27 & Xavier Xufre & poder \\
\hline 26 & EIM 0,15 & $\begin{array}{l}\text { Nobre Guedes suspeito de } \\
\text { fuga ao fisco }\end{array}$ & financeiro \\
\hline 27 & EIM 0,95 & Lista Negra da Guarda & conduta \\
\hline
\end{tabular}

\begin{tabular}{|c|c|c|c|}
\hline 28 & EIM 1,23 & $\begin{array}{l}\text { O enriquecimento } \\
\text { de Duarte Lima }\end{array}$ & financeiro \\
\hline 29 & EIM 1,45 & Processo dos Hemofílicos & poder \\
\hline 30 & EIM 0,45 & $\begin{array}{l}\text { As obras particulares de } \\
\text { Cavaco }\end{array}$ & financeiro \\
\hline 31 & EIM 0,52 & O matadouro da Guarda & poder \\
\hline 32 & EIM 0,32 & INDESP & poder \\
\hline 33 & EIM 0,08 & Fichas falsas na JSD & poder \\
\hline 34 & EIM 0,14 & A Sisa de Murteira Nabo & financeiro \\
\hline 35 & EIM 0,09 & Câmara de Celorico da Beira & poder \\
\hline 36 & EIM 0,39 & O lobby de Gomes da Silva & poder \\
\hline 37 & EIM 0,14 & Os impostos de Judas & financeiro \\
\hline 38 & EIM 0,11 & Caso Saleiro & financeiro \\
\hline 39 & EIM 0,16 & Monte dos Vendavais & financeiro \\
\hline 40 & EIM 0,22 & $\begin{array}{l}\text { O património de Narciso } \\
\text { Miranda }\end{array}$ & poder \\
\hline 41 & EIM 0,19 & JAE & poder \\
\hline 42 & EIM 0,04 & $\begin{array}{l}\text { José Raul dos Santos } \\
\text { acusado de fraude }\end{array}$ & poder \\
\hline 43 & EIM 4,96 & Universidade Moderna & financeiro \\
\hline 44 & EIM 0,03 & José Mota e os subsídios & poder \\
\hline 45 & EIM 0,20 & $\begin{array}{l}\text { As inconfidências } \\
\text { de Sousa Franco }\end{array}$ & conduta \\
\hline 46 & EIM 0,36 & $\begin{array}{l}\text { A família Soares e os } \\
\text { diamantes angolanos }\end{array}$ & financeiro \\
\hline 47 & EIM 4,40 & Saco Azul de Felgueiras & poder \\
\hline 48 & EIM 0,43 & Avelino Ferreira Torres & poder \\
\hline 49 & EIM 0,89 & $\begin{array}{l}\text { Fundação para a Prevenção e } \\
\text { Segurança }\end{array}$ & poder \\
\hline 50 & EIM 0,29 & $\begin{array}{l}\text { Catarina Vaz Pinto em } \\
\text { empresa que subsidiou }\end{array}$ & poder \\
\hline 51 & EIM 0,23 & Saco Azul de Águeda & poder \\
\hline 52 & EIM 6,57 & Isaltino Morais & poder \\
\hline 53 & EIM 6,51 & Casa Pia & sexual \\
\hline 54 & EIM 1,08 & Caso da Mala & financeiro \\
\hline 55 & EIM 0,64 & $\begin{array}{l}\text { Filha do MNE com entrada } \\
\text { facilitada em Medicina }\end{array}$ & poder \\
\hline 56 & EIM 3,94 & Apito Dourado & poder \\
\hline 57 & EIM 0,23 & Amadora Connection & poder \\
\hline 58 & EIM 0,04 & $\begin{array}{l}\text { O licenciamento } \\
\text { da casa da Arrábida }\end{array}$ & poder \\
\hline 59 & EIM 0,08 & $\begin{array}{l}\text { Favorecimentos } \\
\text { na Câmara do Porto }\end{array}$ & poder \\
\hline 60 & EIM 7,58 & Freeport & poder \\
\hline 61 & EIM 0,09 & $\begin{array}{l}\text { Negócios imobiliários } \\
\text { de Judas }\end{array}$ & poder \\
\hline 62 & EIM 1,30 & Portucale & poder \\
\hline 63 & EIM 0,24 & Negócio dos CTT & poder \\
\hline 64 & EIM 0,63 & Bragaparques & poder \\
\hline 65 & EIM 1,32 & $\begin{array}{l}\text { Irregularidades } \\
\text { na Câmara de Lisboa }\end{array}$ & poder \\
\hline 66 & EIM 0,21 & Suspeitas nas SCUT & poder \\
\hline 67 & EIM 0,10 & Caso de Salvaterra & poder \\
\hline 68 & EIM 2,79 & A licenciatura de Sócrates & conduta \\
\hline 69 & EIM 0,99 & Submarinos & poder \\
\hline 70 & EIM 0,13 & Delitos na Câmara do Funchal & poder \\
\hline
\end{tabular}




\begin{tabular}{|c|c|c|c|}
\hline \multicolumn{4}{|c|}{$\begin{array}{l}\text { Casos iniciados no período de Mudança de Ciclo } \\
\text { (2008-atualidade) }\end{array}$} \\
\hline 71 & EIM 6,85 & BPN & financeiro \\
\hline 72 & EIM 0,76 & $\begin{array}{l}\text { Jackpot para o Casino de } \\
\text { Lisboa }\end{array}$ & poder \\
\hline 73 & EIM 0,10 & Projetos da Guarda & financeiro \\
\hline 74 & EIM 0,11 & $\begin{array}{l}\text { O empreendimento da Ponte } \\
\text { Galante }\end{array}$ & poder \\
\hline 75 & EIM 0,27 & $\begin{array}{l}\text { Câmara de Lisboa atribui } \\
\text { casas }\end{array}$ & poder \\
\hline 76 & EIM 0,31 & $\begin{array}{l}\text { Coelho e os negócios da } \\
\text { Mota-Engil }\end{array}$ & poder \\
\hline 77 & EIM 0,06 & Quinta do Ambrósio & poder \\
\hline 78 & EIM 5,98 & Negócio PT/TVI & poder \\
\hline 79 & EIM 0,77 & $\begin{array}{l}\text { Encerramento do jornal de } \\
\text { sexta da TVI }\end{array}$ & poder \\
\hline 80 & EIM 0,57 & Os "cornichos" de Pinho & conduta \\
\hline 81 & EIM 0,27 & $\begin{array}{l}\text { Enriquecimento de Mesquita } \\
\text { Machado }\end{array}$ & poder \\
\hline 82 & EIM 2,10 & Escutas ao Presidente & poder \\
\hline 83 & EIM 6,51 & Face Oculta & poder \\
\hline 84 & EIM 0,45 & Caso Mário Crespo & conduta \\
\hline 85 & EIM 1,54 & Taguspark & poder \\
\hline 86 & EIM 0,49 & O furto dos gravadores & conduta \\
\hline 87 & EIM 0,04 & As eleições no PS de Coimbra & poder \\
\hline 88 & EIM 3,00 & O homicídio de Rosalina & conduta \\
\hline 89 & EIM 1,65 & Caso das Secretas & poder \\
\hline 90 & EIM 0,47 & PPP nas rodoviárias & poder \\
\hline 91 & EIM 0,11 & $\begin{array}{l}\text { Censura a programa da } \\
\text { Antena } 1\end{array}$ & poder \\
\hline 92 & EIM 0,75 & Homeland & financeiro \\
\hline 93 & EIM 2,35 & A licenciatura de Relvas & conduta \\
\hline 94 & EIM 0,15 & $\begin{array}{l}\text { Macário Correia perde o } \\
\text { mandato }\end{array}$ & poder \\
\hline 95 & EIM 0,02 & $\begin{array}{l}\text { Paulo Júlio faz concurso à } \\
\text { medida }\end{array}$ & poder \\
\hline 96 & EIM 1,25 & Swaps & poder \\
\hline 97 & EIM 0,64 & Machete mente ao parlamento & conduta \\
\hline 98 & EIM 0,34 & $\begin{array}{l}\text { Machete pede desculpa a } \\
\text { Angola }\end{array}$ & poder \\
\hline 99 & EIM 0,02 & $\begin{array}{l}\text { Narciso Miranda suspeito de } \\
\text { desvio de fundos }\end{array}$ & financeiro \\
\hline
\end{tabular}

Suportados pelos valores extraídos com recurso à EIM (Escala de Intensidade Mediática), podemos afirmar que a atenção concedida pelos media ao escândalo político em Portugal permite caracterizá-lo como sendo predominantemente de baixa magnitude, havendo 59,6\% de casos com as classificações mais baixas (Micro, Muito Pequeno e Pequeno), 28,3\% nas classificações intermédias (Ligeiro, Brando e Moderado) e apenas 12,1\% nos valores mais elevados (Relevante, Grande e Muito Grande), não tendo sido detetado no período de análise, até 25 de abril de 2014, qualquer caso na classificação "Extrema".

No que diz respeito à duração, em média, cada caso arrasta-se na imprensa, ainda que de forma interrupta, durante mais de quatro anos (a maior duração registada é superior a 19 anos e a menor é de 8 dias, nos periódicos estudados). Este padrão de cobertura jornalística está estreitamente ligado ao andamento dos processos judiciais, o que faz com que a justiça marque não apenas o ritmo como também as incidências mediáticas, influindo sobre a visibilidade dos políticos sob investigação. Assim, as investigações judiciais, buscas, interrogatórios, julgamentos, recursos, novas acusações, etc., compõem os momentos que, independentemente de serem ou não públicos, são suscetíveis de exposição nas capas dos jornais. No fundo, quando se tenta ilustrar a proeminência da justiça face à política, esta ideia fica mais nítida, expondo o fenómeno do escândalo político. A numerosa quantidade de informação proveniente de fontes da justiça induz a que estas procurem reabilitar a sua imagem através de diligências tornadas públicas, mostrando trabalho feito, necessitando por isso de recorrer aos canais mediáticos quando lhes é conveniente.

O processo de escandalização, i.e., a sucessão de fases em que o escândalo político se desenrola, sugere que os casos seguem uma sequência que estipulámos ter início no Pré-escândalo, seguindo-se o momento da Revelação, a Narrativa, o Desfecho e o Pós-escândalo. O "Pré-escândalo" ocorre quando a transgressão ainda circula reconditamente. A "Revelação" é a fase em que surgem as primeiras notícias e em que os media começam a sua cobertura. A "Narrativa" diz respeito ao período da exploração do caso, com entrevistas, investigações, contra-argumentações, explanação de pormenores e detalhes. É sobretudo nesta fase que o escândalo propaga o seu desenvolvimento, à medida que novas abordagens e novos argumentos - não necessariamente novas informações 
- são apresentados, em que se assiste ao fluir dos acontecimentos e mesmo a novas descobertas. O "Desfecho" aponta para o final estipulado do caso, onde a resolução faz diminuir o interesse dos media, podendo esta concernir tanto a uma sentença como a uma demissão, a uma assunção de culpa, a uma comprovação da prevaricação ou, ao invés, até mesmo à ilibação do visado. No fundo, é esta fase que cunha o resultado final do caso. Por fim, o "Pós-escândalo" constitui a fase em que, já desaparecido o escândalo, ele é recuperado esporadicamente e abordado nos media em algumas circunstâncias, como a peleja política entre adversários ou a evocação de um tempo marcado pela sua ocorrência, por exemplo, dado que o muito extenso repositório possibilitado hoje pela Internet acaba por permitir ter à mão qualquer caso, sempre que se afigure necessário, acessível a todos, em qualquer instante. A sequência não é rígida, podendo não se verificar a totalidade das fases em alguns casos. Este encadeamento possibilita-nos constatar que a fase mais expressiva em termos de volume de peças e de número de edições é a Narrativa (com uma média de 36,8 edições por caso nos semanários nacionais que integram o nosso corpus de análise). Embora seja na Revelação que os casos são precipitados, é a Narrativa que constitui maior preocupação para os políticos visados, pois é nesta fase que ocorre a exploração dos temas, onde os detalhes vão sendo adicionados e as novas descobertas jornalísticas vão sendo expostas. É também na Narrativa que se dá maioritariamente o pico dos casos, ou seja, o "auge". Este representa o apogeu da cobertura e pode acontecer em etapas distintas do novelo do escândalo, verificando-se o seu surgimento em apenas três das cinco fases: Revelação (29\%), Narrativa (62\%) e Desfecho (9\%). A análise da cobertura jornalística do escândalo conduz-nos à refutação de uma premissa que tem sido utilizada, demonstrando-se aqui que o auge não deve constituir-se como uma fase autónoma, mas, sim, como um elemento que pode ocorrer em qualquer altura, o que vem, inclusivamente, reforçar o padrão de imprevisibilidade do escândalo político.

As peças jornalísticas sobre o fenómeno, grosso modo, apresentam formatos mais extensos e são tendencialmente colocadas na zona superior das páginas. Em $78 \%$ dos casos analisados, verifica-se que a cobertura mediática é efetuada por mais do que um jornal (o que vem fortalecer, por um lado, a observação do efeito mimético patente na comunicação social e, por outro, a relevância do escândalo para os media). Os géneros jornalísticos mais utilizados em todas as décadas e por todos os jornais são a notícia/reportagem. A notícia não é apenas composta pelos factos que vão sucedendo na rotina quotidiana, mas por informações e enredos que alimentam a história do escândalo, para ser interpretada, enquadrada e narrada pelos jornalistas, informando o público e mantendo-o em linha com o caso. A opção por noticiar um acontecimento, ou dar relevo a um assunto, não só resulta da ponderação de valores-notícia presentes nos media em geral, mas também das singularidades editoriais de cada redação. Um desses critérios de noticiabilidade prende-se com a personalização, o que vem permitir ao público identificar-se com heróis ou vilões, "colorindo" acontecimentos e situações (Correia: 1997: 186). 
Figura 3

Evolução dos géneros notícia/reportagem e opinião em cada década democrática.

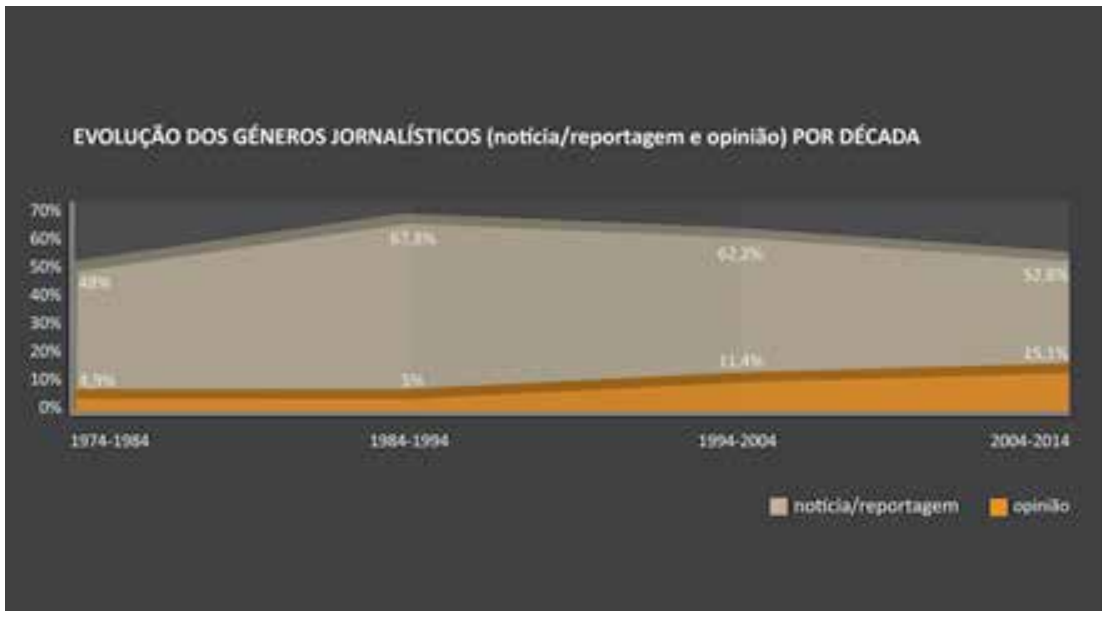

Apesar da sua predominância, os géneros notícia/reportagem têm sofrido um decréscimo no seu valor percentual, tendo as peças de opinião, por contraste, vindo a aumentar a sua representação, como é percetível a partir do gráfico 3. Isso deve-se sobretudo ao conjunto de colaboradores permanentes do espaço opinião, de onde se destaca a participação cada vez maior de jornalistas, passando estes a ter um duplo papel: de informadores do público (e zeladores da verdade informativa, alicerçada em critérios de objetividade) e de especialistas interessados em analisar e avaliar as consequências políticas dos casos.

Dos protagonistas envolvidos em casos de escândalo político, os mais visados pelos media são os que têm ou tiveram ligações ao poder governativo, podendo-se daqui extrair o maior enfoque que lhes é dado pela comunicação social, dada a sua visibilidade e escrutínio mediático, como também a proximidade ao poder e à decisão executiva. Na mesma linha, autarcas e agentes partidários seguem-se na lista, o que leva a enfatizar a conclusão de que os escândalos recaem mais frequentemente sobre os políticos que se encontram no poder, seja ele governativo, autárquico ou partidário, o que pode ser justificado pela visibilidade mediática que o poder atrai. Esta é, por isso, para os políticos, uma faca de dois gumes: apreciável quando abonatória; evitável quando nociva ou adversa.

Quando procurámos cotejar qual o tom das peças publicadas face aos protagonistas do escândalo, observando quer os espaços de opinião, quer as peças de cariz informativo, verificámos que o tom conferido aos políticos visados é negativo em 78,3\% dos casos, notando-se um aumento gradual ao longo do período democrático, com especial ênfase para a última década, quando ocorreu um crescimento mais acentuado quer do volume de peças quer do número de casos, verificando-se uma subida drástica do tom negativo. Os dados obtidos permitem relacionar o aumento do número de casos com um impacto pejorativo na sua cobertura quando colocada em saliência a variável do tom atribuído aos protagonistas. Esta perspetiva apresentada pelos órgãos de informação, justa ou injustamente, concorre para a má imagem da classe política. Não se estranha, por isso, que, no inquérito já referido, quando perguntámos a 1436 pessoas se confiam na classe política portuguesa, só $9 \%$ tenham respondido afirmativamente. Do mesmo modo, quando perguntámos se os media atingem mais audiência com a cobertura de escândalos, ou seja, se lucram com a sua inclusão, 93,6\% responderam afirmativamente.

\section{Notas de remate}

Os temas suscitados neste trabalho, no seu conjunto, são parte fundamental para se refletir sobre a importância do escândalo político na democracia portuguesa e a relevância dos media no mesmo contexto. Terminamos, por isso, este ponto com a questão que fez despertar o nosso interesse pelo assunto, procurando nesta tese proceder à desocultação de algumas matérias confinadas aos bastidores dos media e da política: dependerá necessariamente o escândalo da ocorrência prévia de uma transgressão ou poderá ele nascer de um simples rumor ou de uma mentira construída para ser depois massificada? 
É iniludível que o escândalo não se subordina impreterivelmente à ocorrência de uma infração, mas, sim, a uma narrativa que tanto pode ser real como ficcionada. Nesse sentido, a verdade e a mentira são indistintas para a deflagração de um caso. Esta ilação é ainda mais preocupante se atendermos à observação de Castells (2013: 337), de que “o escândalo é o instrumento eleito para resolver as batalhas políticas do nosso tempo."

Mas não deixa de ser menos enfática a ilação de que o escândalo político, hoje, ocorre apenas por via da ação dos media. Estes, como vimos, espoletam os casos, expõem os visados e criam uma narrativa que chega ao público. Os media tendem a dar maior atenção aos casos e a expor mais volumosamente e por mais tempo a sua cobertura. Concorrem para tal a "utopia positiva" do ethos profissional do jornalista, mas também a convicção de que o tema ajuda a captar a atenção das audiências, facto muito valioso num tempo em que a crise financeira se abateu com estrondo sobre o setor, acentuando a encruzilhada deontológica e comercial com que os media se confrontam.

\section{Bibliografia}

Allern, S., Pollack, E. (eds.) (2012). Scandalous! The mediated construction of Political Scandals in four nordic countries. Gothenburg: Nordicom.

Baum, M. A. (2002). Sex, lies and war: how soft news brings foreign policy to the inattentive public. Am. Polit. Science Review, 96, 91-109.

Bell, A. (1998). The discourse structure of new stories. In A. Bell \& P. Garret, (eds.) (1998), Approaches to Media Discourse. Oxford: Blackwell Publishers, 64-104.

Brants, K. (2005). Quem tem medo do infotainment?. Media \& Jornalismo, 7(7), 39-58.

Cabrera, A. (2001). Missão Paz em Timor: percurso de um pseudo-acontecimento. A. Cabrera, C. Ponte, R. Santos, \& N.Traquina (eds), O Jornalismo Português em Análise de Casos. Lisboa: Editorial Caminho.

Cabrera, A. (2011). Jornais, Jornalistas e Jornalismo (séculos $\mathrm{xIX} e \mathrm{xx}$ ). Lisboa: Livros Horizonte.

Castells, M. (2013). O Poder da Comunicação. Lisboa: Fundação Calouste Gulbenkian.
Correia, F. (1997). Os Jornalistas e as Notícias. Lisboa: Caminho.

Cunha, I. F. (2012a). Análise dos Media. Coimbra: Imprensa da Universidade de Coimbra.

Cunha, I. F. (2012b). A cobertura televisiva de partidos, Candidatos e Temas nas Legislativas. In R. Figueiras, (coord.), Os Media e as Eleições Europeias, Legislativas e Autárquicas de 2009. Lisboa: Universidade Católica Editora.

Cunha, I. F. (2014). Visibilidade da cobertura jornalística da corrupção política e indicadores de opinião pública. In I. F. Cunha \& E. Serrano, (coords), Cobertura Jornalística da Corrupção Política: Sistemas políticos, sistemas mediáticos e enquadramentos legais. Lisboa: Aletheia Editores, 371-420.

Cunha, I. F. (2015a). Media e padrões da corrupção política: os casos Freeport e Face Oculta. Media \& Jornalismo. Coimbra: Imprensa da Universidade de Coimbra, 14 (1), 45-64.

Cunha, I. F. (2015b). Da desdemocratização’ da Europa: democracia, media e corrupção política. Intercom - Revista Brasileira de Ciências da Comunicação, 38 (1). 
Ekstrom, M. (2000). Information, Storytelling and Attractions: TV journalism in three modes of communication. Media Culture \& Society 22 (4), 465-492.

Ekstrom, M., \& Johansson, B. (2008). Talk Scandals. Sage Publications. 30 (1), 61-79.

Fenton, N. (2010). New media, Journalism and Democracy: Figments of a neo-liberal imagination?. Media \& Jornalismo, 17 (9/2): 41-52.

Fidalgo, J. (2009). O Lugar da Ética e da Auto-Regulação na Identidade Profissional dos Jornalistas. Fundação Calouste Gulbenkian/ Fundação para a Ciência e a Tecnologia.

Figueiras, R. (coord.) (2012). Os Media e as Eleições: Europeias, legislativas e autárquicas de 2009. Lisboa: Universidade Católica Editora.

Fitoussi, J-P, \& Rosanvallon, P. (1997). A Nova Era das Desigualdades. Oeiras: Celta Editora.

Fontecuberta, M. de (1999). A Notícia: Pistas para compreender o mundo. Lisboa: Editorial Notícias.

Lull, J., \& Hinerman, S. (eds.) (1997). Media Scandals. Morality and desire in the popular culture marketplace. Cambridge: Polity Press.
Mancini, P. (1993). Between trust and suspicion: how political journalists solve the dilemma. European Journal of Communication, 8, 33-51.

Markovits, A. S., \& Silverstein, M. (eds.) (1988). The Politics of Scandal: Power and process in liberal democracies. New York: Holmes \& Meier. Rieffel, R. (2003). Os Media e a Vida Política. Sociologia dos Media. Porto: Porto Editora.

Thompson, J. B. (2002). O Escândalo Político. Poder e visibilidade na era da mídia. Petrópolis: Editora Vozes.

Tuchman, G. (1978). Making News: A study in the construction of reality. New York: Free Press. 